too much into the hands of professors who were anatomists but not surgeons, to the lasting detriment of their practical training. The old system may have tended to make the student too much a disciple of empiricism, but the scientific book-reading medico of to-day would benefit much by a little smattering of rational empiricism, the education of commonsense reading.

Dr. Weatherly had realised in his own case the value of apprenticeship to a sound practitioner, and how it afforded the young student the means of watching the progress of his patients, the relative significance of their symptoms, and the value of treatment. The older practitioner, observing the progressively greater precision of the implements of science as applied to the diagnosis of disease, was often forced to wonder how without their aid he had managed to find out what was the matter with his patients, or to pull them successfully through many grievous ailments. And yet while envying his younger brethren their scientific attainments, while listening to their learned papers and accounts of difficult diagnoses successfully achieved, he was sometimes bound to feel that it would have been well for them to have encountered some of the difficulties which fell to his lot before science had so asserted her sway. What was particularly lacking now was the training of the eye to detect minute, yet tangible and significant, differences in form, appearance, expression, and functional activity. The love of scientific detail might tend to the greatest accuracy in the diagnosis of a patient's physical signs, while the general condition of the patient failed to receive adequate notice and attention. As Erichsen once said, the educated student of to-day was thus making himself actually less useful to the sick man than his less perfectly trained predecessor, who by reason of his more general observation was often a superior antagonist to disease.

Another recent development which Dr. Weatherly viewed with some misgiving was the enterprise of the modern druggist. This remarkably active person had now a way of making up drugs into tabloids, neatly wrapped up with the dose to be given and the diseases to be cured writ large; he was sending out pamphlets broadcast, with descriptions of complaints which could be cured by this or that new drug with some grand-sounding Latin or Greek name, and the medical practitioner was in constant receipt of useful diaries with long lists of therapeutic agents manufactured by one advertising firm or another. The consequent tendency to pocket prescribing might in some cases be useful, but surely it tended too much towards putting patients into the hands of the advertising chemist, while it was at the same time getting the doctor out of the art of prescribing, which could be learnt only by practical experience. It was to be feared also that some of the new and fashionable drugs were ousting the older and simpler remedies which in the hands of the last generation of practitioners were found so useful and effective; of these, Dr. Weatherly thought that calomel in particular had fallen into undeserved neglect.

With regard to surgery the progress made since the invention of anæsthetics and antiseptics was truly remarkable and calculated to astonish the surgeon of sixty years ago. So great had it been that anatomically there was now nothing impossible to the surgeon, and he was only stopped by physiological considerations. But it was to be feared that as a consequence he tended to be too long in the performance of operations, to give too much attention to elaboration and detail, and too little to the danger of shock; he might even learn something from the celerity and dexterity of his predecessors. Again, there was undoubtedly too great a tendency to use the knife on all occasions as a means of diagnosis. Of course, this was much easier than any other method of examination, but would it not in many cases be better that the surgeon should give his powers of observation a chance, and at the same time learn by the conservatism of his older brethren? Then, again, in gynæcological practice it was true that the use of pessaries had at one time been carried to great excess, but there was now the danger that the pendulum had swung too far in the opposite direction, and that the knife and needle were a little too much in evidence. Similarly the knowledge that injuries could be so rapidly repaired led to excessive zeal in the use of the long forceps, so that with the announcement of the safe arrival of a healthy first-born there was too often the accompaniment of rupture of the mother's perineum.

\section{THE PHARMACOLOGICAL ACTION OF THE THYROID GLAND.}

By ROBERT HUTCHISON, M.D., M.R.C.P.,

Demonstrator in Physiology, London Hospital Medical College.

THE recent promotion of the thyroid to an official position in the British Pharmacopoia makes this a suitable time to state what is known as to its pharmacological action. More especially is this the case owing to the fact that the literature relating to the thyroid has recently swelled to such enormous proportions that he who runs is certainly no longer able to read it, whilst embedded in that literature there are yet a number of facts and observations which have a very direct bearing on the therapeutic use of the substance. It may, therefore, be permitted to one who, from the special nature of his own investigations, has been obliged to read all that has been written on the subject, to discuss briefly the present state of our knowledge as to the physiological effects of the administration of the thyroid, and the bearing of that knowledge upon its use as a medicinal agent.

\section{I.-Effects upon Metabolism.}

Shortly after the thyroid began to be used in the treatment of myxœdema, it was noticed that the urine of patients who were taking it contained a large excess of urea $\left({ }^{1}{ }^{2}\right)$. More exact investigations were soon set on foot $\left({ }^{3}{ }^{17}\right)$ which showed that not only was the elimination of nitrogen increased in patients who were taking thyroid, but that the amount eliminated very often exceeded considerably the amount ingested in the corresponding period of time. Obviously, therefore, a tissue rich in nitrogen, presumably muscle, had undergone an increased destruction. The loss of weight in such patients was, however, much greater than any mere destruction of proteid tissue would account for, and attention was next directed to the intake and output of respiratory gases $\left(\begin{array}{ll}18 & 22\end{array}\right)$. The results showed that under thyroid administration there is a great rise in the amount of oxygen taken in, and a very considerable, but relatively not so great increase in the amount of $\mathrm{CO}_{2}$ given out. The obvious inference was that the thyroid leads to a greatly increased consumption of the body fat.

Briefly, then, it may be said that the effect of the administration of the thyroid is to increase oxidation in the body ; it makes the tissues, as it were, more inflammable, so that they burn away more rapidly. The products of the disintegration of the nitrogenous tissues appear in the urine almost entirely in the form of urea, uric acid, $\left(\begin{array}{llll}\tau & 12 & 13 & 22\end{array}\right)$ and the xanthin bases $(\tau)$ being neither regularly nor appreciably increased, while the products of the fat destruction are eliminated as carbonic acid by the lungs, and water by the kidneys. It is important to note the large increase in the excretion of water which occurs under thyroid administration. Diuresis is often one of the first effects of the drug, and a considerable proportion of the very sudden fall of weight which is often to be observed at the outset of a course of thyroid treatment is to be attributed simply to loss of water. Thyroid feeding seems to make the tissues drier. On cessation of the treatment this loss of water is very quickly replaced, and is accompanied by a corresponding increase in weight.

It is not sufficient merely to know that the thyroid increases tissue metabolism; we must inquire more minutely into the details of its action. Under normal conditions, as is well known, there is a constant destruction of proteids, carbohydrates, and fats going on in the body. If the amount of proteids in the food be increased, there may be a temporary storage of nitrogen in the body, but very soon equilibrium is again established, and the output becomes equal to the intake. If we increase the amount of carbohydrates and fat in the diet we may succeed in storing some of the excess as fat, but we find also that we have diminished the amount of proteid broken down in the body. In the words of the physiologists, carbohydrates and fats have a proteid-sparing action. Now it is important to inquire, What effect has the thyroid upon all this? Does it merely hurry on the whole process so that the turnover in the body is as it were increased without any disturbance in the relative destruction of proteid and fat occurring, or does it increase one of these more than the other? In other words, Does thyroid feeding lead to a 
quantitative or to a qualitative alteration in metabolism or to both?

Now this is no mere academic question suitable for discussion in the physiological lecture room; it has very direct practical bearings. The use of the thyroid as a remedy in obesity has recently attained a wide prevalence. The ideal "antifat" would be something which increased the power of the tissues to consume fat without at the same time causing an increased destruction of proteid. Does the thyroid do this? Obviously not, for as we have seen its use is followed by an increased elimination of nitrogen as well as of carbonic acid. Granted then that both fats and proteid tissues tend to be broken down, on which of these does the thyroid act most powerfully? Is there any direct action on the proteid tissues or are these only attacked when there is no longer enough fat left to exercise a protective influence on the proteids? Towards the settlement of this question much research has recently been directed, but as yet the results of it are rather contradictory. Some writers $\left({ }^{15}\right)$ assert that the thyroid has a specific action on the proteid tissues, and a few even go so far as to maintain that under thyroid administration the proteid-sparing power of fat and carbohydrates is suspended. Others believe that the proteids are only attacked secondarily and after fat has been to a large extent got rid of, and it has certainly been shown by careful observations on cases of obesity that great loss of weight can occur while there is yet less nitrogen being eliminated than is ingested $\left({ }^{9}{ }^{17}\right)$. For my own part I think there is a good deal to be said for the view that the increased elimination of nitrogen which is observed at the commencement of thyroid feeding is due to destruction of circulating proteid, and that the fixed proteid tissues are only attacked when the store of fat has been considerably diminished. The practical inference is that in treating cases of obesity by thyroid feeding the diet should not be much restricted, and especially that nitrogenous matter should be abundantly represented in it. The safest method of procedure, of course, would be to estimate the amount of nitrogen in the diet, and the amount eliminated, and to stop the treatment or diminish the dose whenever the latter exceeded the former, but that method is too laborious to be practicable.

In its action on metabolism the thyroid is unique amongst medicinal agents. No other drug that we are acquainted with is capable of increasing the oxidation processes of the body in such a way. It may best be compared, perhaps, to the effect of muscular exercise. The thyroid increases metabolism without putting one to the necessity of performing muscular work. Hence its usefulness as an aid in combating an excessive accumulation of fat. It may also be compared to the effect of the toxic substances which produce fever. Fever, however, seems to have a more specific action on proteid metabolism than the thyroid has, but a fuller investigation of the chemical nature of the active constituent of the thyroid may be expected to throw some light on the toxalbumins which produce pyrexia. Indirectly, also, the effects of thyroid administration tend to confirm the view that the rise of temperature in fever is mainly due to a diminished heat loss, for by thyroid feeding one may increase tissue metabolism to an amount sufficient to produce a loss of weight of as much as $8 \mathrm{lbs}$. in a week, yet without causing the temperature to rise more than half a degree.

It is not yet determined whether the active constituent of the thyroid exerts its effects on the tissues directly or through the intervention of the nervous system. In favour of the belief that the latter method is the real modus operandi is the very minute quantity of the substance which is sufficient to produce powerful effects. If one regards the tissues as held in leash, as it were, by the trophic centres of the nervous system in much the same fashion as the heart is by the vagus, then it would not be difficult to understand how, if under the action of the thyroid this influence were temporarily suspended, the tissues would run off, so to speak, and a great increase in metabolism result. But this is pure speculation. I have tried to find whether the thyroid has any directly stimulating effect on the activity of cells by causing yeast to produce fermentation in a sugar solution containing some thyroid extract, but did not find that the rate of fermentation was increased thereby. Of course an experiment like that is by no means conclusive, for it might very well be that the thyroid had no stimulating influence on vegetable cells.
Whether the thyroid influence be exerted on the tissues directly or only through the medium of the nervous system, its essential nature would seem to consist in a hastening on of the life-history of the cells. Cell division occurs more rapidly, and the cell reaches maturity and passes into old age in a shorter time than normal. The reverse of this process occurs typically in myxœdema, where many of the cells never seem to reach a mature stage. Thus the subcutaneous tissue becomes filled with cells in an embryonic stage, and when the old hairs fall out the cell division which should lead to the formation of new ones ceases to occur, and the patient becomes bald. The thyroid exerts its beneficial influence by hastening on the life-listory of the cells. This explains, also, its action in backwardness of growth in children and the good effect which it sometimes exerts in such skin diseases as psoriasis and ichthyosis, where the final death and casting off of the epidermic cells seems to be much delayed.

It is interesting to reflect that the secretion of the thyroid is constantly finding its way into the circulation, and must there exercise its effects on metabolism. One is tempted to speculate whether the different states of nutrition in different individuals may not be due to variations in the activity of their thyroids. In cases of simple goître one is almost compelled to believe that there must be a great demand for the secretion, and that the hypertrophy of the thyroid is a response to the demand. This might explain the very remarkable effects of thyroid feeding in cases of simple goitre. In such cases, especially if recent and the subject roung, administration of thyroid by the mouth is followed by a steady diminution in the size of the goître, the latter tending to increase again when the treatment is stopped. The thyroid given by the mouth lessens the demand for the natural product, and the hypertrophy of the thyroid passes off. Bruns $\left({ }^{9}\right)$ has made observations in dogs with goître which confirm this view. He examined a piece of the goître microscopically, and found that it presented the characters of a gland which was over-secreting. After thyroid treatment the goître almost disappeared, and on examining a fresh portion he found that the gland had now resumed its normal characters. The advocates of the thyroid theory of exophthalmic goître will no doubt find confirmation of their views in the observations of Matthes $\left({ }^{1 *}\right)$, who has found that a study of the respiratory and urinary excretions in that disease show that metabolism is increased in the same way as in thyroid feeding.

The occurrence of glycosuria as a result of thyroid administration has frequently been observed, and recent experiments tend to show that the glycosuria may be of the alimentary type. Thus Bettmann, in the Berliner klinische Wochenschrift, No. 24, 1897, found that if, after a week of thyroid feeding, one gives a patient roo g. or so of glucose on an empty stomach glycosuria results. He was successful in obtaining it in about half of the cases in which the experiment was tried, although the same patient showed no glycosuria if a similaramount of glucose was given without a previous course of thyroid. Such experiments seem to indicate that the thyroid may sometimes affect carbohydrate metabolism in such a way as to diminish the power of the tissues to utilise sugar.

\section{II.-Effects on the Circulation and Bioon.}

Increased rapidity of the heart's action is perhaps the most constant of the effects observed from thyroid administration. The action of the drug can hardly be said to be manifested, unless the pulse rise by ro or more beats per minute. Along with increased rapidity one often observes other disturbances of the heart's action during thyroid administration, such, for example, as irregularity, palpitation, or even threatenings of failure. The experimental study of these effects has recently been attempted, but curiously enough, the results have been entirely negative. Vamossy and Vas ${ }^{31}$ ) found that even strong solutions of iodothyrin had no effect at all upon the strength, rhythm, or rate of the isolated frog's heart, or on the heart of rabbits or dogs in situ, and I have myself obtained entirely negative results on intravenous injections of colloid matter. $\left({ }^{32}\right)$ Nevertheless, the clinical fact of increased rapidity of pulse during thyroid feeding remains, and a conceivable explanation of the negative results of experiment is that the heart is acted on secondarily by some substance produced during the 
exaggerated metabolism which follows thyroid administration.

This specific effect of the thyroid upon the heart renders caution necessary in administering the drug to patients with cardiac debility. In cases of obesity, where the fatty change may also have affected the heart, this is especially necessary. It has also been suggested that this action of the thyroid would be likely to render its administration useful in cases of functional bradycardia.

It has been found that the active part of the thyroid has no effect on the blood pressure. This has been shown by Vamossy and Vas for iodothyrin, and by myself for the colloid matter. The fall of hlood pressure which occurs when decoctions of the gland are injected is mainly due to the action of organic extractives, and a similar fall follows the injection of extractives from other glands or of a weak solution of Liebig's extract of meat. It has further been shown $\left({ }^{45}\right)$ that these bodies do not affect the blood pressure at all if they are administered by the mouth instead of by intravenous injection. Notwithstanding this experimental evidence the sphygmometer shows a slight fall of blood pressure in patients who are under the influence of the thyroid. The fall seems to be due to enfeeblement of the heart rather than to any peripheral dilatation of blood ressels.

The effects of thyroid administration upon the blood have been studied both clinically and experimentally. Perry $\left({ }^{33}\right)$ found that the only change which resulted from the administration of medicinal doses in man was an increase in the relative number of the lymphocytes (that is, a physiological leucocytosis). MacPhail and Bruce $\left.{ }^{24}\right)$ found in cases of insanity that a dose of twelve tabloids daily caused a fall in the red corpuscles of about $7 \frac{1}{2}$ "per hæmic unit" and a diminution in the amount of hæmoglobin to the extent of 6 per cent. The administration of iron at the same time prevented the loss of hæmoglobin and brought about a slight increase in the number of the red cells. Bruns $\left({ }^{35}\right)$ has also seen chlorosis set in during the treatment of a case of acromegaly by means of thyroid.

On the other hand, Lebreton ${ }^{36}$ ) has compared the blood in a case of myxodema before and after thyroid feeding, and has found all the constituents increased and a greater relative increase also in the lymphocytes. Donath $\left({ }^{6}\right)$ has found that in rabbits small doses improved the condition of the blood, while large doses caused the destruction of the red corpuscles to the extent of from 14 to 22 per cent. Von Vamossy and Vas $\left({ }^{31}\right)$ gave to a dog varying doses of iodothyrin by the mouth, subcutaneously and by injection into a vein. They found that no effect was produced unless large doses were injected into the vein. In that case they observed a transitory fall in the specific gravity of the blood and in the red corpuscles and hæmoglobin, whilst there was a more distinct rise in the number of the leucocytes. It would seem, therefore, that small doses of thyroid produce no effect on the blood of healthy persons, while large doses cause an increased destruction of blood corpuscles just as of other cells. In myxcedema, on the other hand, the stimulus which thyroid feeding gives to all growth and division is manifested in the blood by a rise in the number of the corpuscles.

\section{III.-Excretion of the Active Constituent of the} THYROID.

The active const ituent of the thyroid appears to be excreted entirely by the kidney. I have found iodine present in the urine of a dog within three hours after the administration of I g. of the colloid matter. On the other hand, I have never been able to detect any iodine in the bile of animals to which thyroid preparations have been given, even in large doses. Baumann has also detected iodine in the urine of dogs whose thyroids had been removed and to whom iodothyrin had been administered $\left({ }^{41}\right)$. It is difficult, however, to detect iodine in the urine of patients who are taking thyroid preparations. Thus von Jaksch $\left({ }^{39}\right)$ failed to find that element in the urine of a patient after the administration of as many as fifty thyroid tabloids. This may be due to the well-known power that the normal thyroid possesses of laying hold of iodine when given either as an inorganic salt or in the form in which it occurs in thyroid preparations, and of storing it up and thus preventing its excretion. If a healthy thyroid be present, therefore, iodine does not appear in the urine unless a large excess has been administered. This explains how Blum $\left({ }^{42}\right)$ has been able to detect iodine in the urine of normal dogs to whom roo sheep's thyroids had been given at once.

On the other hand, the absence of the thyroid in myxœdema prevents the storage of iodine in the body, and accordingly it is more easy to detect that substance in the urine of cases of myxœdema which are under thyroid treatment. Whether the iodine is excreted in an organic or inorganic form must at present be left undecided. For my own part I have found that it can only be detected after incineration of the urine, and that it is present in a form soluble in hot or cold alcoliol. Blum $\left(^{42}\right)$, however, states that he has found it present in an inorganic form. The question is of importance as throwing light on whether the organic iodine compound in the thyroid is entirely broken down in the body or whether some of it is excreted unchanged.

The excretion of the active constituent of the thyroid appears to be a gradual one. At all events there is no doubt that the action of the drug continues, often for severa days, after the administration of it has ceased. That this is not to be attributed to the thyroid of the patient laying hold of the substance, and gradually giving it out is to be inferred from the fact that the after-action is as noticeable in cases of myxœdema, in which presumably the thyroid is totally inactive, as in normal subjects.

\section{IV.-Dosage of Thyroid Preparations.}

It must be admitted that we have as yet got no satisfactory method of standardising thyroid preparations. One cannot do so by making a given quantity of any thyroid preparation equivalent to a given weight of fresh gland because the amount of the active constituent present in any given weight of fresh gland may vary very greatly. Nor can we take the colloid matter as the standard, for, as I have shown elsewhere, there is reasen to believe that it also may be of varying composition. It has been suggested that the activity of thyroid preparations should be gauged by the amount of iodine they contain, but this also may prove fallacious, for there is not yet any certain proof that the presence of iodine is essential to the activity of the thyroid at all.

Practically the difficulty is got over if the preparation be made from a sufficiently large mass of glands. The individual inequalities in these are then able to neutralise one another. Thus one finds that the composition of the colloid matter as found in the market is almost constant, and the thyroid powder of the new Pharmacopoia will no doubt be so too, if prepared in fairly large quantities at a time.

I have prepared some of the new liquor thyroidei according to the directions given in the Pharmacopaia, and find that it contains about $4 \frac{1}{2}$ per cent. of colloid matter. An ordinary dose of the latter is about $0.1 \mathrm{~g}$., and that would be contained in about 37 minims of the liquor. I am therefore of opinion that the dose of the latter recommended in the Pharmacopaia ( 5 to 15 minims) is too small, and would better have been given as 15 to 60 minims. Otherwise the liquor seems to be as good a fluid preparation of the thyroid as could have been devised.

Whatever the preparation employed experience seems to show that it is best to give it in small doses and frequently, rather than in large quantities at longer intervals. It is also very necessary to feel one's way in the administration of the thyroid, beginning with a small dose, and gradually increasing it. This is necessitated by the fact that idiosyncrasy plays a large part in the reaction which patients show to the drug, and the extent of the reaction in any particular case can never be foretold. The symptoms produced by over-actionheadache and pains in the limbs, nausea, diarrhœa, palpitation, etc., and which are classed under the term "thyroidism",-have been partly ascribed by Lanz $\left({ }^{43}\right)$ not to any specific action of the thyroid, but to the presence in the preparation employed of toxic substances produced by putrefaction. Cunningham $\left({ }^{45}\right)$ has also recently made out a pretty strong case for this view. On the other hand, it has been denied by Zum Busch ( ${ }^{44}$ ) as the result of his experience in about a thousand cases that this explanation of thyroidism is the correct one. For my own part I think there is some truth in both positions. There is no doubt that the thyroid is a substance very prone to undergo putrefactive change, and 
some of the symptoms of thyroidism, notably the alimentary group-for example, nausea and diarrhœa-are, I think, to be explained by the presence of toxic products in the preparation employed. Since I have used preparations made by myself, of whose freshness I could be certain, I have seen nothing of this group of symptoms in the cases I have treated. On the other hand, I believe that the headache, pains in the limbs, and cardiac symptoms are due to a specific action of the thyroid, or are produced by some product of the exaggerated metabolism which it excites and that no degree of purity in the preparation employed is a guarantee that such symptoms will not arise. Seeing, moreover, that the organic iodine compound in the thyroid will stand prolonged boiling without having its activity in the least impaired, it ought to be possible to prepare a powder for administration which shall be entirely free from any products of decomposition. Whether the method of preparation of the thyroid powder of the Pharmacopoia eliminates the possibility of any toxic products remaining in it is, I should think, decidedly open to question.

Postscript.-Since the above article was written there has appeared in this JourNal (July 9th, 1898) a paper by Dr. William MacLennan describing a new thyroid preparation ("thyroglandin"). As that paper contains a number of what (in my judgment) are serious errors as to the facts of the chemistry of the thyroid and the nature of its active constituent, I feel that I ought to make a short reference to it. Dr. MacLennan asserts that the thyroid contains two important principles - an iodoglobulin and iodothyrin-and that both of these are requisite to produce the specific effects of the gland itself. This assertion is quite unfounded in fact. As I have shown elsewhere, the fresh thyroid contains only one iodine-containing compound-namely, the colloid matter. This consists of a proteid part (possibly a globulin) combined with an organic compound of iodine (crude iodothyrin), and the latter compound is split off on hydrolysis of the colloid. The specific effects of the thyroid can be produced by the administration either of the colloid matter as a whole or of the iodothyrin split off from it. The effects produced by both preparations are identical, provided an equivalent dose of each is employed. Further, the colloid matter contains all the activity of the thyroid, the extractives being incapable of producing any of the specific effects of the gland.

It is not the case that all of the processes which have been devised for separating the active constituent of the gland result either " in the destruction of the iodoglobulin entirely, or in the partial separation of the iodothyrin only." In the preparation of the colloid matter, as described by myself, the glands are extracted with dilute caustic soda without the aid of heat. The colloid matter is so soluble in alkalies that it goes entirely into the solution, and if any traces of iodothyrin happen to have been split off from it in the gland, these are also dissolved. The subsequent addition of acetic acid throws down the colloid, and it is afterwards dried without having undergone any decomposition whatever. Furthermore, this separation is accomplished without any other substance of "a useless or objectionable nature" being contained in the final product.

The process which Dr. MacLennan describes as that by which "thyroglandin" is prepared will be perceived at once by anyone conversant with the chemistry of the thyroid to result in the extraction of the colloid matter, plus the salts, extractives, and any other substance which happens to be present, and which is soluble either in water or in boiling caustic soda solution. As the salts and extractives have been shown to be " useless," and as the other substances (for example, products of decomposition) may very easily be objectionable, I entirely fail to see the superiority of this process over those already in existence. That the product is simply an impure form of the colloid matter I entertain no doubt at all, and by the administration of $\mathrm{I} \frac{1}{2} \mathrm{gr}$. of the latter thrice daily I have over and over again obtained quite as marked results as were produced by double that dose of thyroglandin. I therefore cannot regard the latter preparation as in any way superior to those with which the profession is already familiar.

BIBLIOGRA PHY.

For the convenience of other workers I append a classified list of papers bearing upon the pharmacological action of the thyroid. The numbers bearing upon the pharmacological actir
cerrespond to references in the text.
I. Influence of the Thyroid on Metabolism : Nitrogen Elimination. -1 Napier, Lancet, vol. ii. r893. 2 Ord and White, ibid. 3 Douglas, Proc. Roy. Soc: Edin,, vol. xx, p. 330, 1895. "'Bleibtreu and Wendelstadt, Deut. med. Woch., 22, 1895. 5 Dennig, Minch. med. Woch., Bd. 42, 17 , I895. ' Donath, Virchow's A rchiv, Bd. I44, sup. heft., p. 253, 1896. (with full references). 7 Richter, Centraib. f. inn. Med., No. 3, 1896. 'Grawitz, Münch. med. Woch., No. I4, +896 . 9 Schöndorff, Pfiuger'\& Archiv, Bd. 63, 8896 ; and Bd. 67, r897, p. 395 . 10 Treupel, Mïnch. med. Woch., No. 6, 1896 (good references). 11 Dinkler, Miinch. med. Woch. No. 22, x896. 12 Irsai, Vas, and Gara, Deut. med. Woch., No ${ }^{28,}{ }^{8896}$ (with literature). ${ }^{13}$ David, Zeitsch. f. Heilkunde, xvii. p. 437, 1896. 14 Schifi,

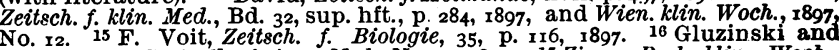
Lemberger, Centralb. f. inn. Med., No. 4, 1897. ${ }_{17}$ Zinn, Berl. klin. Woch. No. 27, 1897. 17* Matthes, Verhandl. d. 15ten Cong. f. inn. Med., 1897, p. 232 Gas Interchange: 18 Magnus Lévy, Deut. med. Woch., No. 31, 1896.19 Magnus Lévy, Verhand. $\dot{d}$. 14ten Cong. $f$. inn. Med., Wiesbaden, 1896.20 Thiele and Nehring, Zeitsch. $f$. klin. Med. xxx, p. 41, 1896.21 Leube, Sitzungsbericht. d. phys. med. Gesellsch. z. Würzburg, No. $7,1896$.

1896, p. 186 (Influence on Uric Acid Excretion). Wiener med. Blätter, xix, 8 II. Influence on the Circulation.-29 Haskovec, Wiener med. Blatter, $\mathrm{xix}, 8$ 1896. 30 Schäfer and Oliver, Journ. of Physiology, xviii, p ${ }_{32}^{277}$, 1895.
vutchison, Journ. of Physiology, vol. xxiii, 1898 .

III. Influence on the Blood. ${ }_{33}$ Perry, New York Med. Rec., p. 289,1806 34 MacPhail and Bruce, Lancet, October, $1894 .{ }^{35}$ Bruns, Neurolog. Centralbl.,
No. Ir, r895. 36 Lebreton (quoted in Limbeck's Palhologie des Blutes, 2 nd Ed., p. 337). 37 Donath, Virchow's Archiv, Bd. 144, sup. hft., p. 253, 1896. 38 V. Vamossy and Vas, op. cit. (31)

IV. Excretion of Active Principle. -39 Ewald, von Jaksch, and others, Verandl. d. rsten Cong. f. inn. Med., 1896 (Discussion on Thyroid Medication). 40 Frenkel, Berl. klin. Woch., No. 37, 1896.49 Baumann and Goldmann, Miinch. med. Woch., No 47, r896. 42 Blum, Münch. med. Woch., 8 and $9,1898$. V. Dosage, Thyroidism, etc.-43 Lanz, Deut. med. Woch., 1895, No. 37.
44 Zum Busch, Deut. med. Woch., r896, No. 3r. 45 Cunningham, Journ. of Experimental Medicine, iii, p. 147,1898 .

\section{REMARKS ON A CASE OF PENETRATING GUN- SHOT WOUND OF THE ABDOMEN : IMMEDIATE LAPAROTOMY : SUTURE OF STOMACH : RECOVERY.*}

BY JOHN WARD COUSINS, F.R.C.S., M.D.LoND. Senior Surgeon to the Royal Portsmouth Hospital and the Portsmouth and South Hants Eye and Ear Infirmary.

Penetrating wounds of the abdomen must be regarded at all times as severe and dangerous injuries, but gunshot wounds, from the serious damage they inflict upon the internal structures, are always surrounded by special dangers and complications. In civil practice wounds of this class are uncommon accidents, but on the field of battle they constitute 15 per cent. of the total number of gunshot injuries, and their fatal character is shown by the fact that the majority of the men wounded in this region never reach the military hospitals, but rapidly sink from shock and hæmorrhage. ${ }^{1}$ In these injuries the danger is in direct proportion to the damage done to the internal organs. Sometimes the projectile penetrates the peritoneal cavity and lodges within it ; at other times it traverses the abdomen, and then lodges in some other part of the body or emerges at a second wound.

On October 26 th, 1897 , I met in consultation Drs. Sykes and Richardson of Gosport on the case of B. L., a girl, aged 16 , who had received a severe wound of the abdomen by the accidental explosion of a six-chambered revolver. At the moment of discharge she was holding the weapon in both hands with the muzzle pointing to the region of the stomach. The bullet entered the abdomen 2 inches to the point about midway between it and the ninth costal cartilage, and passed out on the right side of the spinal process of the twellth dorsal vertebra. It did not penetrate the clothes behind, but dropped out of them as they were being removed. The missile was a cylindro-conoidal bullet, half an inch in length, five-eighths of an inch in thickness, and it weighed r25 gr: It was flattened on one side near the point, and the facet measured a quarter of an inch in diameter. Severe pain immediately followed the accident, the patient was cold and livid, and the pulse rapid and wiry, about r $5 \circ$ per minute. She was

moved to the Royal Portsmouth Hospital. When seen two hours after the accident she had vomited a good deal of blood, and appeared in a state of severe collapse. After some subcutaneous injections of brandy and strychnine, she somewhat rallied. Ether was then at once administered, and abdominal section performed. The abdomen was opened by an incision through the wound of entrance, four inches in length, and two inches below and parallel with the costal margin The black and ragged discoloration extended through the parietal track into the abdominal cavity. The omentum presented, but beyond it the track of the bullet coutang the traced. After carefula raising this structure, and then rotating the stomach inwards, an irregular ound its edges were dark coloured and ragged; and it was surrounded by

* Abstract of an Address delivered before the South-East Hants Medical Society, April, r8g8. 